\title{
Characteristics of organic pollutants in discharged industrial waste in Korea \\ - Focuse on metallic and plastic manufacturing processes and wastewater treatment plants -
}

Jin-Mo Yeon, Young-Yeul Kang, Woo-Il Kim ${ }^{\star}$, Sun-Kyoung Shin, Seong-Kyeong Jeong, Yoon-A Cho, Na Kim and Min-Sun Kim

National Institute of Environmental Research of Environmental Research, Incheon 404-170, Korea (Received August 17, 2012; Revised September 20, 2012; Accepted September 20, 2012)

\section{국내 사업장 폐기물 중 유기오염물질의 배출특성 연구 \\ - 금속과 플라스틱 제조공정 및 폐수처리시설 중심으로 -}

\author{
연진모 · 강영렬 · 김우일` · 신선경 · 정성경 · 조윤아·김 나· 김민선 \\ 국립환경과학원 환경자원연구부 자원순환연구과 \\ (2012. 8. 17. 접수, 2012. 9. 20. 수정, 2012. 9. 20. 승인)
}

\begin{abstract}
In this study, PCDD/PCDFs, PAHs and PCBs in wastes from metal, plastic and wastewater treatment facilities were analyzed. The concentrations of PCDD/PCDFs ranged from 7.37 432.20 ng-TEQ/kg in fly ash, 0.51 855.01 ng-TEQ/kg in incinerated ash and 0.37 385.81 ng-TEQ/kg in dust. Dioxin content was lower, compared to data in foreign countries. PAHs concentration was in the range of $0.0075 \sim 2.9225 \mathrm{mg} / \mathrm{kg}$ for process sludge and $0.0035 \sim 1.6716 \mathrm{mg} / \mathrm{kg}$ for wastewater sludge, which satisfied all of the two standards (Nap, Ant, B(a)F:4/0.8, Phen, B(a)A:5/1, Flt:10/2.5, B(a)P:4.5/0.9) of the Marine Environment Management Act. PAHs concentration in process sludge and wastewater sludge were slightly lower than those abroad. According to the analysis of seven types of PCBs (in comparison with the first standard, $0.15 \mathrm{mg} / \mathrm{kg}$ ), concentration was found in the range of $0.0 \sim 0.65 \mathrm{mg} / \mathrm{kg}$, while PCB-52, PCB-101, PCB-138, PCB-153 and PCB-180 isomers were detected in excessive value in some machine oil and hydraulic fluid.

요 약: 본 연구는 국내에서 배출되는 금속과 플라스틱 및 폐수처리시설 폐기물 중 유기오염물질류인 $\mathrm{PCDD} / \mathrm{PCDFs}$, $\mathrm{PAHs}, \mathrm{PCBs}$ 의 배출 특성을 파악하고자 수행하였다. $\mathrm{PCDD} / \mathrm{PCDFs}$ 의 농도는 비산재가 7.37 432.20 ng-TEQ/kg, 소각재는 0.51 855.01 ng-TEQ $/ \mathrm{kg}$, 분진의 $0.37 \sim 385.81 \mathrm{ng}-\mathrm{TEQ} / \mathrm{kg}$ 범위로 나타났 으며 외국의 분석결과에 비해 다이옥신의 함량농도가 낮은 것으로 조사되었다. PAHs의 농도는 공정오니 의 평균 함량농도가 $0.0075 ~ 2.9225 \mathrm{mg} / \mathrm{kg}$, 폐수처리오니는 $0.0035 \sim 1.6716 \mathrm{mg} / \mathrm{kg}$ 범위로 나타나 해양환 경관리법의 규제기준을 모두 만족하였으며, 공정오니 및 폐수슬러지의 PAHs 농도는 외국의 경우와 비교 하여 다소 낮은 것으로 조사되었다. 또한, 해양환경보전법에서 관리하고 있는 PCBs 7 종을 분석한 결과
\end{abstract}

$\star$ Corresponding author

Phone : +82-(0)32-560-7507 Fax : +82-(0)32-560-7414

E-mail : woolr@korea.kr 
(제 1 기준 $0.15 \mathrm{mg} / \mathrm{kg}$ 비교) 검출농도는 $0.0-0.65 \mathrm{mg} / \mathrm{kg}$ 으로 나타났으며, 일부 기계유 및 작동유에서 PCB52, PCB-101, PCB-138, PCB-153 및 PCB-180 개별이성체가 초과되었다.

Key words: PCDD/PCDFs, PAHs, PCBs, sludge, dust, ash

\section{1. 서 론}

경제와 산업이 발달함에 따라 많은 종류의 화학물 질이 제품생산에 사용되고 있으며, 이에 따라 유해폐 기물 발생량도 증가하고 있다. 유해물질이 인간에 미 치는 독성, 위해성 등의 영향을 고려하여 미국, 일본 등 선진국과 바젤협약, 스톡홀름협약 등 국제기구에서 는 유해폐기물 중 규제대상 유해물질을 확대하고 규 제기준을 강화하고 있는 실정이다. 그러므로, 국내에 서도 유해폐기물의 효율적인 관리하고 국민의 건강과 환경을 유해물질로부터 보호하기 위해 관리대상 유해 오염물질의 항목을 확대하고 규제기준을 설정하여 운 영하는 것이 필요하다.

우리나라를 비롯한 미국, 일본, 독일 등 선진국에서 는 유해폐기물의 분류를 발생원, 유해물질 함유여부, 유해특성 등으로 분류하고 이들 폐기물을 배출특성, 성상 등에 따라 목록화하여 관리하고 있다. 그러나 우 리나라는 유해물질관리 항목수가 선진국에 비해 적고, 유해폐기물 배출목록의 세분화가 미흡한 실정이다. 그 러므로 선진국 및 국제기구의 유해폐기물 규제기준과 시험 항목 등을 종합적으로 검토하여 우선적으로 추 가 - 관리하여야 할 유해폐기물 중 미규제 유해물질 항 목 및 시험방법을 마련하였으며, 환경부에서는 국내 지정폐기물의 효율적 관리와 유해폐기물로 인한 2 차 환경오염 방지를 위해「폐기물 유해성평가 관리체계 선진화」사업을 추진하고 있다. ${ }^{1-2}$

특히 향후 보다 엄격한 관리가 필요한 미규제 유기 오염물질은 대표적으로 환경 중에서 매우 안정하고 식물과 동물의 지방에 축적되며 인간에게 급 - 만성, 유전 독성 및 발암성을 가지는 다이옥신류(polychlorinated dibenzo-p-dioxin; PCDDs, polychlorinated dibenzo furans; PCDFs), 다환방향족탄화수소(polyclyclic aromatic hydrocarbons; PAHs), 폴리염화비페닐(polychlorinated biphenyls; $\mathrm{PCBs}$ ) 등이 있다. $\mathrm{PCDD} / \mathrm{PCDFs}$ 는 화합물 의 제조, 펄프 및 종이제조, 도시 및 의료폐기물 소각, 야금공정과 석탄연소 등의 공정에서 비의도적으로 생 성 및 배출 되며, ${ }^{3} \mathrm{PAHs}$ 는 산업폐수, 하수, 강우 및 대기 침적 등 다양한 경로를 통해 하 - 폐수종말처리장
으로 유입되며, 낮은 용해도와 입자상 물질에 대한 높 은 친화력으로 인해 수 처리 공정을 거치는 동안 90\% 이상이 슬러지에 흡착되어 하 - 폐수로부터 제거 되기 때문에 슬러지에 포함된 PAHs에 대한 연구가 국내외 연구 자료에 의해 많이 수행되었다. ${ }^{4-8} \mathrm{PCBs}$ 는 전기절연성이 우수한 특성으로 인해 다양한 제품으로 생산되었으나 발암성, 생식독성 등의 독성이 알려진 이후 1970 년대부터 생산 및 사용을 금지하였고, 바젤 협약, 스톡홀름 협약 등에서 국제적인 현안으로 다루 고 있다. 이들 물질은 신경계, 면역계, 내분비계 등에 미치는 영향이 크다고 알려져 있으며, 내분비계장애물 질(endocrine disrupting chemicals; EDCs) 또는 잔류성 유기오염물질(persistent organic pollutants; POPs)등으 로 분류되어 많은 관심의 대상이 되고 있다. ${ }^{9-10}$ 최근 환경부는 ' 12.8 월부터 $\mathrm{PCBs}$ 농도가 $2 \mathrm{ppm}$ 이상인 절연유 함유기기의 수출입 금지 등을 주요 내용으로 하는 $\ulcorner$ 잔류성유기오염물질 관리법」시행령 및 시행규 칙을 공포하였다. 또한, 런던협약에 따라 우리나라는 2012년부터 슬러지의 해양투기가 금지되어 하수처리 장의 슬러지를 공업화 또는 자원화 및 소각처리확대 등 다양한 대책을 추진 중에 있다.

본 연구는 금속과 플라스틱 제조공정과 폐기물처리 시설 - 공공폐수처리시설 - 공공급수시설에서 발생되는 폐기물을 배출하는 국내 22 개 업체를 선정하여 현지 조사하고, 오니류, 소각재, 폐유 등 폐기물 시료의 채 취 및 $\mathrm{PCDD} / \mathrm{PCDFs}(17), \mathrm{PAHs}(7)$ 및 $\mathrm{PCBs}(7)$ 항목의 분석을 통해 배출 특성을 파악하여, 유기오염물질의 관리방향을 제시하고자 하였다.

\section{2. 시료채취 및 분석방법}

\section{1. 유해폐기물의 시료채취}

올바로 시스템에 등록된 사업장의 폐기물 자료, 화 학물질 배출량자료 및 유럽 연합의 폐기물 배출 목록 (European Waste Catalogue, EWC)을 토대로 금속과 플라스틱의 형태 - 물리 - 기계적 표면처리 시 발생하는 폐기물(EWC 12)과 폐기물처리시설 - 공공폐수처리시 설 - 공공급수시설에서 발생되는 폐기물(EWC 19)을 
Table 1. Status of sample according to the EWC* classification (EU waste code)

\begin{tabular}{|c|c|c|}
\hline Code & EU Waste List & Total \\
\hline 12 & Wastes from shaping and physical and mechanical surface treatment of metals and plastics & 7 \\
\hline 1201 & Wastes from shaping and physical and mechanical surface treatment of metals and plastics & 6 \\
\hline 1203 & Wastes from water and steam degreasing processes (except 11) & 1 \\
\hline 19 & $\begin{array}{l}\text { Wastes from waste management facilities, off-site waste water treatment plants and the preparation of water } \\
\text { intended for human consumption and water for industrial use }\end{array}$ & 30 \\
\hline 1901 & Wastes from incineration or pyrolysis of waste & 11 \\
\hline 1902 & Wastes from physico/chemical treatments of waste (including dechromatation, decyanidation, neutralisation) & 3 \\
\hline 1908 & Wastes from waste water treatment plants not otherwise specified & 12 \\
\hline 1911 & Wastes from oil regeneration & 3 \\
\hline \multirow[t]{2}{*}{1913} & Wastes from soil and ground water remediation & 1 \\
\hline & Total (sample) & 37 \\
\hline
\end{tabular}

Table 2. Classification of samples by analysis items

\begin{tabular}{|c|c|c|c|}
\hline Sample code & PCDD/PCDFs & $\begin{array}{c}\text { PAHs } \\
\left(7{\text { chemicals })^{1)}}^{1)}\right.\end{array}$ & $\begin{array}{c}\text { PCBs } \\
(7 \text { isomers })^{2)}\end{array}$ \\
\hline Sludges & - & 16 & - \\
\hline Dust & 3 & - & - \\
\hline $\mathrm{ASh}$ & 8 & - & - \\
\hline Waste oil & - & - & 4 \\
\hline Machine oil & - & - & 6 \\
\hline Total & 11 & 16 & 10 \\
\hline
\end{tabular}

1) Naphthalene, phenanthrene, anthracene, benzo[a]pyrene, fluroanthene, benzo[a]anthracene, benzo[b]fluoranthene

${ }^{2)}$ IUPAC Number 28, 53, 101, 118, 138, 153, 180

배출하는 사업장을 선정하여 현지조사 하였다. 선정된 22 개 업체를 방문하여 오니류, 소각재, 폐유 등 37 건의 폐기물 시료를 채취하고 폐기물 발생량, 처리현 황 및 폐기물 분석자료 등을 조사하였다. Table 1과 같이 EWC 공정별로 시료채취 현황을 나타내었다. 분 석대상 시료에서 유해 유기물질류 함유 가능성을 검 토하여 PCDD/PCDFs 11 건, PAHs 16 건, PCBs 10 건을 분석하였다. Table 2 는 폐기물 시료의 분석현황 을 나타내었다.

\section{2. 시료분석방법}

폐기물 관리법에서 관리되고 있지 않은 유기물질 류인 $\mathrm{PCDD} / \mathrm{PCDFs}, \mathrm{PAHs}, \mathrm{PCBs}$ 의 함량 분석방법 은 국립환경과학원에서 수행된 「지정폐기물중 신규 유해물질의 항목 설정 및 시험방법 확립에 관한 연 구 ${ }^{11-12}$ 를 준용하여 수행하였다. $\mathrm{PCBs}$ 는 $\mathrm{GC} / \mathrm{ECD}$ 로 분석하였으며 $\mathrm{PAHs}$ 와 $\mathrm{PCDD} / \mathrm{PCDFs}$ 는 $\mathrm{GC} / \mathrm{MSD}$ 및 $\mathrm{HRGC/HRMS}$ 에 의한 선택이온검출법(SIM)으로
검출하여 분석하였다. Fig. 1에 유기물질의 분석방법 절차를 나타내었다.

\section{3. 결과 및 고찰}

본 연구에서는 현행 폐기물관리법으로는 관리되고 있지 않으나 잔류성유기오염물질관리법과 해양환경관 리법에서 관리되고 있는 미규제 유기물질류(PCDD/ $\mathrm{PCDFs}, \mathrm{PAHs}, \mathrm{PCBs})$ 의 분석결과를 국립환경과학원에 서 수행한 「지정폐기물중 유해물질 규제항목 확대에 관 한 연구(I), (II)」 ${ }^{13-14}$ 의 제안 기준과 비교 · 검토하였다.

\subsection{PCDD/PCDFs 함량특성}

금속과 플라스틱의 형태 - 물리 - 기계적 표면처리 시 발생하는 폐기물 중 분진(1 건), 폐기물의 소각, 열분 해 시 발생하는 비산재(3 건), 소각재(5 건), 분진(2 건) 등의 폐기물 11 건에 대하여 조사하였다.

비산재의 다이옥신 농도는 7.37 432.20(평균 229.63) $\mathrm{ng}-\mathrm{TEQ} / \mathrm{kg}$, 소각재는 0.51 855.01 (평균 180.55) ng$\mathrm{TEQ} / \mathrm{kg}$, 분진은 0.37 385.81 (평균 133.70) ng-TEQ/kg 범위로, 평균농도로 비교했을 때 비산재가 높은 것으 로 나타났다.

POPs에 대한 규제 기준을 설정하여 관리하는 POPs 지첨서가 바젤협약에서 채택되었는데 다이옥신 함유 폐기물의 규제기준은 $15,000 \mathrm{ng}-\mathrm{TEQ} / \mathrm{kg}$ 으로 설정하고 있고, 일부 선진국을 중심으로 폐기물 중 다이옥신 규 제 기준을 설정하여 관리하고 있다. 본 연구에서 다이 옥신의 농도가 총계 기준안인 $15,000 \mathrm{ng}-\mathrm{TEQ} / \mathrm{kg}$ 에 초 과하지 않았다.

특히, 폐분쇄틀 및 분쇄물에서 발생하는 분진에서 $385.81 \mathrm{ng}-\mathrm{TEQ} / \mathrm{kg}$ 로 가장 높게 검출되었으며, 야금공 


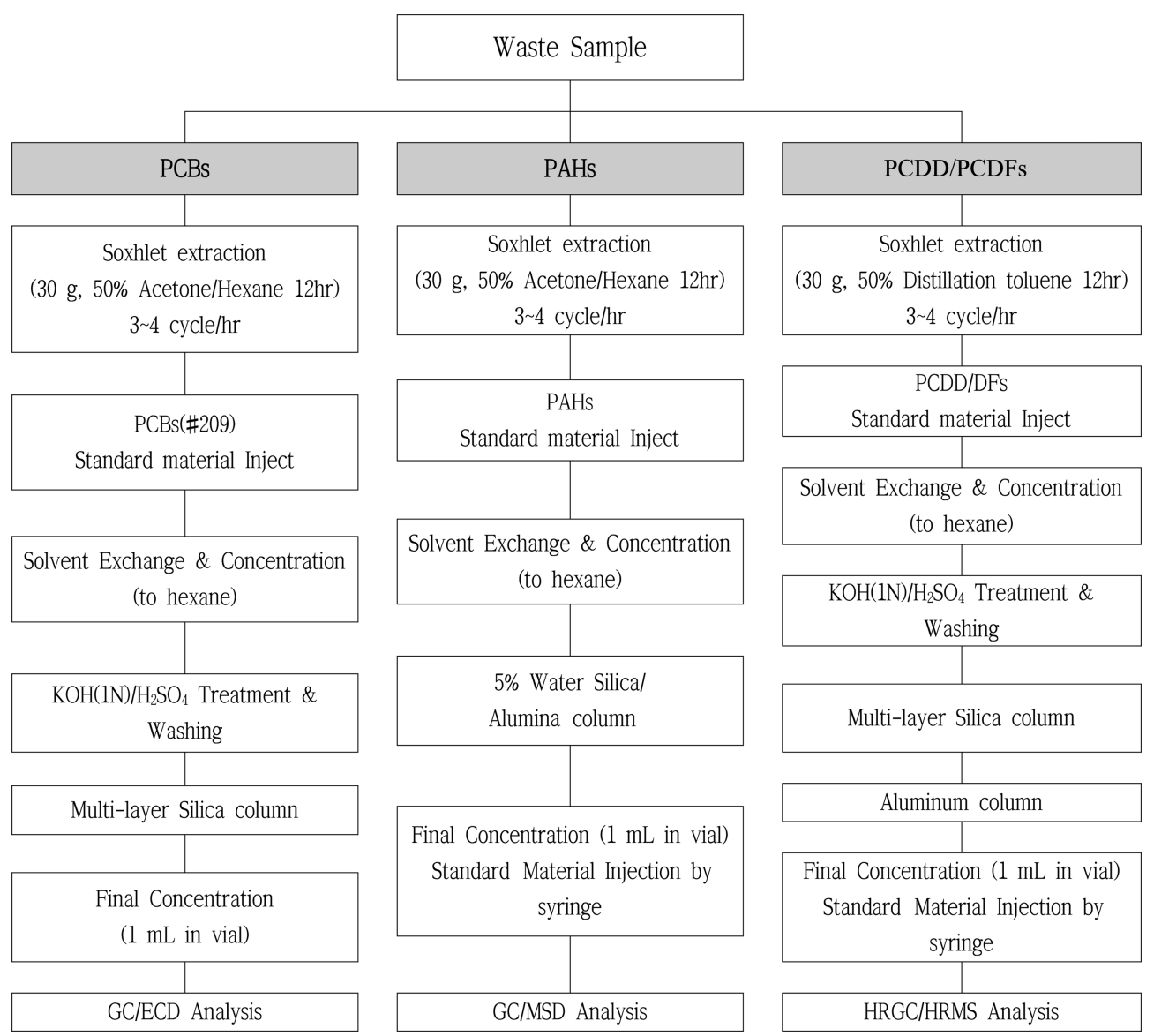

Fig. 1. Scheme of analysis method on targeted organic substance.

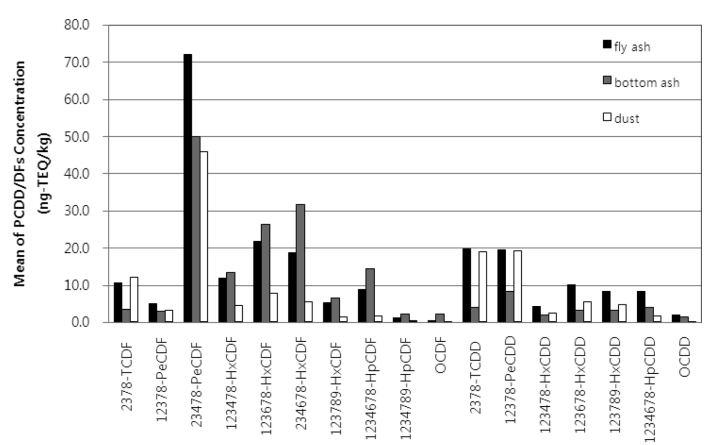

Fig. 2. Congener homologues pattern of PCDD/Fs in fly ash, bottom ash and dust.

정 중 다이옥신이 발생하는 것으로 보고되고 있다 ${ }^{3}$. 비산재, 소각재, 분진 등 각각 다이옥신의 이성질체 검출패턴을 확인한 결과 모두 유사하게 나타났다(Fig. 2). 이러한 특성은 폐기물의 소각, 열분해하는 유사한 공정에서 발생하는 폐기물이므로, 비슷하게 나타나는
Table 3. Comparison of PCDD/PCDFs concentration (ng-TEQ/ g) range in other studies ${ }^{16-22}$

\begin{tabular}{lll}
\hline \multicolumn{1}{c}{ Samples } & \multicolumn{1}{c}{ Sites } & PCDD/PCDFs range(mean) \\
\hline \multirow{2}{*}{ Soil } & Jordan $^{16}$ & N.D 1.031 $(0.344)$ \\
& Germany $^{17}$ & $0.005 \sim 0.638(0.193)$ \\
\hline \multirow{2}{*}{ Sediment } & Belgium-France $^{18}$ & $0.001 \sim 0.012(0.006)$ \\
& Japan $^{19}$ & $0.006 \sim 0.009(0.008)$ \\
\hline \multirow{2}{*}{ Sludge } & Japan $^{19}$ & $0.016 \sim 0.018(0.017)$ \\
& Korea $^{20}$ & $0.005 \sim 0.031(0.015)$ \\
Cinder & & $0.021 \sim 5(2.511)$ \\
& Japan $^{19,21-22}$ & $0.007 \sim 6.997(3.502)$ \\
Fly ash & & $0.059 \sim 2.5(1.280)$ \\
Bottom ash & This Study & $0.074 \sim 0.432(0.23)$ \\
Dust & & $0.0005 \sim 0.855(0.181)$ \\
\hline
\end{tabular}

경항을 보이고 있는 것으로 판단된다.

$\mathrm{PCDD} / \mathrm{PCDFs}$ 의 함유특성을 살펴보면, 비산재, 소각 
Table 4. The result of PAHs concentration $(\mathrm{mg} / \mathrm{kg})$ in process sludges and wastewater sludges

\begin{tabular}{|c|c|c|c|c|c|c|c|c|c|c|c|c|c|c|c|c|}
\hline No. & S-1 & $\mathrm{S}-2$ & PS-3 & PS-4 & PS-5 & WS-1 & WS-2 & WS-3 & WS-4 & WS-5 & WS-6 & WS-7 & WS-8 & WS-9 & 1 & WS-11 \\
\hline PAHs & \multicolumn{5}{|c|}{ Process sludge $(n=5)$} & \multicolumn{11}{|c|}{ Wastewater sludge $(\mathrm{n}=11)$} \\
\hline Int & N.D & N.D & N.D & .0215 & N.D & N.D & 0.0013 & N.D & N.D & N.D & N.D & N.D & N.D & 0.0063 & N.D & N.D \\
\hline he & N.D & N.D & 0.0051 & 0.1606 & 0.0009 & 0.0023 & 0.0053 & 0.0016 & 0.0005 & 50.0028 & 0.0007 & 0.001 & N.D & 0.0496 & 6 & 20 \\
\hline Flu & N.D & N.D & 0.0061 & 10.48 & 0.0057 & 0.0021 & 0.005 & 0.0014 & N.D & 0.0023 & N.D & N.D & N.D & 0.18 & 30.0 & .0123 \\
\hline ce & N.D & N.D & 0.0208 & 1.7357 & 0.0326 & 0.0064 & 0.0212 & 0.0045 & 0.0009 & 90.0035 & N.D & N.D & N.D & 0.7 & 0. & 54 \\
\hline Acy & N.D & N.D & N.D & 0.0269 & N.D & N.D & 0.0008 & N.D & N.D & N.D & N.D & N.D & N.D & 0.0075 & 0.0007 & N.D \\
\hline ap & N.D & N.D & 0.0860 & 0.4630 & 0.0781 & 0.0036 & 0.0533 & 0.0040 & 0.0033 & 30.0009 & 0.0018 & 0.0025 & N.D & 0.6 & o & 16 \\
\hline Chy & N.D & N.D & 0.0007 & 7 N.D & N.D & N.D & N.D & N.D & N.D & N.D & N.D & N.D & N.D & $\mathrm{N}$. & N.D & 0.0005 \\
\hline (a) & $\mathrm{N}$ & J.D & 0.001 & N.D & N.D & N.D & & & & N.D & 0.0091 & $\mathrm{~N}$. & N.D & $\mathrm{N}$ & N.D & D \\
\hline Pyr & N.D & N.D & 0.0015 & 50.0014 & N.D & 0.0008 & 0.0026 & N.D & N.D & 0.0023 & 0.0009 & N.D & N.D & 0.0004 & 0.003 & 0018 \\
\hline Flt & N.D & N.D & 0.0015 & 50.0011 & N.D & 0.0005 & 0.0003 & N.D & N.D & 0.0033 & N.D & N.D & N.D & 0.0005 & 0.0050 & 0.0025 \\
\hline $\mathrm{D}(\mathrm{a}) \mathrm{A}$ & 0.0030 & 0.0029 & 0.003 & 0.0048 & 0.0032 & N.D & N.D & N.D & N.D & 0.0007 & N.D & N.D & 0.0027 & 7 N.D & N.D & N.D \\
\hline $\mathrm{B}(\mathrm{a}) \mathrm{P}$ & N.D & N.D & 0.0011 & 0.0040 & N.D & N.D & N.D & N.D & N.D & N.D & N.D & N.D & N.D & N.D & N.D & N.D \\
\hline (k)F & r & N.D & 0.00 & 30.0 & N.D & N.D & $\mathrm{N}$ & 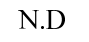 & $\mathrm{N}$ & N.D & N.D & $\mathrm{N}$. & N.D & N.D & I.D & N.D \\
\hline $\mathrm{B}(\mathrm{b}) \mathrm{F}$ & N.D & N.D & 0.0008 & 0.0029 & N.D & N.D & N.D & N.D & N.D & N.D & N.D & N.D & N.D & N.D & N.D & N.D \\
\hline 3(g)P & 0.0037 & 002 & 0.00 & 70.005 & 0.0037 & 0.0007 & N.D & & ND & 0.0010 & .0007 & N.D & 0.0024 & 4 N.D & J.D & N.D \\
\hline (c)P & 0.0019 & 0.0023 & 0.0023 & 30.0048 & 0.0023 & N.D & N.D & N.D & N.D & 0.0007 & 0.0005 & N.D & 0.0022 & 2 N.D & N.D & N.D \\
\hline
\end{tabular}

इPAHs 0.00860 .00750 .13662 .92250 .12650 .01640 .09420 .01150 .00470 .01750 .01370 .00350 .00731 .67160 .35490 .1171

*Ant:anthracene, Phe:phenanthrene, Flu:fluorene, Ace:acenaphthene, Acy:acenaphtylene, Nap:naphtalene, Chy:chrysene, B(a)A:benzo( $\alpha$ ) anthracene, pyr:pyrene, Flt:fluoranthene, D(a)A:dibenzo(a,h)anthracene, B(a)P:benzo( $\alpha)$ pyrene, B(k)F:benzo(k)fluoranthene, B(b)F :benzo( $\beta$ ) fluoranthene, B(g)P:benzo(g,h,i)perylene, I(c)P:indeno(1,2,3cd)pyrene

재, 분진 등 검출된 $2,3,4,7,8-\mathrm{PeCDF}$ 가 각 시료의 전 체 TEQ값의 28 34\%로 차지하는 비율이 제일 높은 것으로 나타났다. 또한, 다이옥신류보다는 퓨란류의 농도가 비교적 높게 검출되었으며 다이옥신 패턴에서 $\mathrm{PeCDF}$ 의 높은 농도경향과 비슷하게 나타났다. ${ }^{15}$

본 연구에서 검출된 $\mathrm{PCDD} / \mathrm{PCDFs}$ 의 농도수준을 기 존 국내 및 외국 조사와 비교하여 Table 3에 나타내었 다. 우리나라와 일본 등 슬러지와 퇴적물에서 보다는 다소 높았다. ${ }^{19-20}$ 그러나 요르단과 독일의 토양, 일본 의 소각재 등에서 조사된 다이옥신 농도에 비하면 비 산재, 소각재, 분진의 다이옥신의 함량농도가 낮은 것 으로 조사되었다. ${ }^{16-17,19,21-22}$

\section{2. $\mathrm{PAHs}$ 함량특성}

여러 매체의 혼합물로 함유된 PAHs는 잠재적 발암 성이 있음이 밝혀졌으며 국제화학물질안전성계획 (International Programme on Chemical Safety, IPCS)에서 는 33 개의 개별화합물을 독성학적 영향 및 노출 관련 자료의 유효성을 평가하기 위하여 선정하고 있다. ${ }^{23} \mathrm{US}$ $\mathrm{EPA}$ 는 16 종의 $\mathrm{PAHs}$ 를 주요 우선관리대상 오염물로 분류하여 총량농도로 규제하고 있으며 현재 규제 대상 은 naphthalene(Nap), phenanthrene(Phe), anthracene

Vol. 25, No. 6, 2012
(Ant), benzo $(\alpha)$ pyrene $(\mathrm{B}(\alpha) \mathrm{P})$, fluoranthene $(\mathrm{Flt})$, benzo $(\alpha)$ anthracene $(\mathrm{B}(\mathrm{a}) \mathrm{A})$, benzo $(\beta)$ fluoranthene $(\mathrm{B}(\mathrm{b}) \mathrm{F}) 7$ 종 이다. 런던협약의 규제대상으로도 7 종이 제 1 기준과 제 2기준으로 되어 있고, 국내 해양환경관리법 시행규 칙 별표 8 해양배출처리기준 제 12 조 제 2 항에도 제 1 기준과 제 2기준으로 제시되어 있다.

시료 16 건은 공정오니, 폐수처리오니에서 채취한 시료로 Table 4에서 보는 것과 같이 16 종 $\mathrm{PAHs}$ 의 분 석결과를 정리하였다. 공정오니의 평균 함량농도는 $0.0075 \sim 2.9225 \mathrm{mg} / \mathrm{kg}$, 폐수처리오니는 0.0035 1.6716 $\mathrm{mg} / \mathrm{kg}$ 범위로 나타나 국내 해양 투기 제 1기준/2기준 은 (Nap, Ant, B(a)F:4/0.8, Phen, B(a)A:5/1, Flt:10/ $2.5, \mathrm{~B}(\mathrm{a}) \mathrm{P}: 4.5 / 0.9)$ 이며, 본 연구에서 채취한 시료 중 16 종 PAHs 농도는 모두 기준 이내로 나타났다.

본 연구에서 검출된 $\mathrm{PAHs}$ 의 농도수준을 기존 외국 자료와 비교하여 나타내었다(Table 5). 공정오니의 $\mathrm{PAHs}$ 농도 $(0.64 \mathrm{mg} / \mathrm{kg})$ 는 중국의 산업슬러지의 농도 $(0.67 \mathrm{mg} / \mathrm{kg})$ 와 비슷한 수준을 나타내었고, ${ }^{27}$ 폐수슬러 지의 PAHs 농도 $(0.21 \mathrm{mg} / \mathrm{kg})$ 는 다른 나라들의 하수 슬러지 및 중국의 슬러지의 농도와 비교하여 다소 낮 았다. ${ }^{24-27}$ 전체적으로 공정오니 및 폐수슬러지의 PAHs 농도는 외국의 경우와 비교하여 다소 낮은 것으로 판 
Table 5. Comparison of PAHs concentration $(\mathrm{mg} / \mathrm{kg})$ range in other studies ${ }^{24-27}$

\begin{tabular}{lll}
\hline \hline \multicolumn{1}{c}{ Samples } & \multicolumn{1}{c}{ Sites } & PAHs range (mean) \\
\hline & Canada $^{24}$ & $2.2 \sim 79(11.8)$ \\
Sewage sludge & Germany $^{25}$ & $2 \sim 15(7.1)$ \\
& Spain $^{25}$ & $1.1 \sim 5.5(3)$ \\
& China $^{26}$ & $2.47 \sim 25.92(8.31)$ \\
\hline Industrial sludge & & $0.07 \sim 2.01(0.67)$ \\
Mixed-flow sludge & & $0.17 \sim 15.19(2.33)$ \\
Enterprise sludge & China $^{27}$ & $0.11 \sim 3.27(1.67)$ \\
River sludge & & $1.3 \sim 1.3(1.3)$ \\
Process sludge & & $0.01 \sim 2.92(0.64)$ \\
Wastewater sludge & This study & $0.004 \sim 1.67(0.21)$ \\
\hline
\end{tabular}

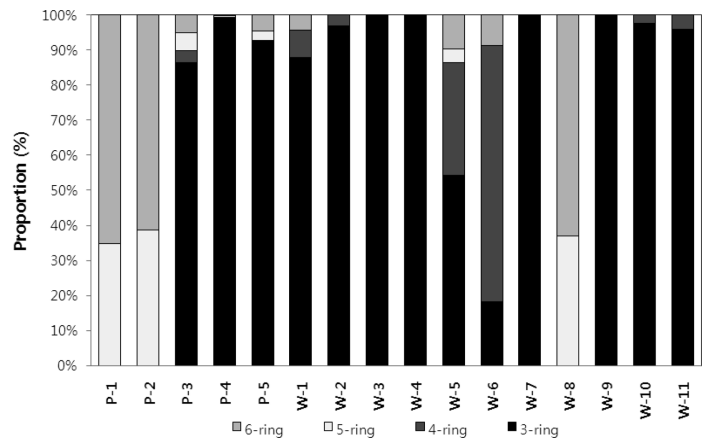

Fig. 3. Distribution of PAHs with four rings of process sludges and wastewater sludges.

단된다.

또한, 공정오니와 폐수처리오니의 고리갯수별 PAHs 의 분포특성을 나타내었다(Fig. 3). PAHs 16 종 중 벤젠 고리가 1 3 개인 PAHs에는 anthrancene, phenanthrene, fluorene, acenaphthene, acenaphtylene, naphtalene, 4 개 인 PAHs에는 chrysene, benzo $(a)$ anthracene, pyrene, fluoranthene, 5 개인 PAHs는 dibenzo( $a, h)$ anthracene, benzo $(a)$ pyrene, benzo $(k)$ fluoranthene, $\operatorname{benzo}(b)$ fluoranthene, 6 개인 PAHs는 benzo $(g, h, i)$ perylene, indeno $(1,2,3 c d)$ pyrene이 있다. 대부분의 시료에서 PAHs 16 종 중 휘발성과 고리의 수가 적은 저분자 3 개인 $\mathrm{PAHs}$ 는 acenaphthene $>$ naphthalene $>$ fluorene $>$ phenanthrene $>$ acenaphtylene $>$ anthracene 순으로 높게 나타났다. 다 양한 제조공정에서 발생되는 폐기물인 슬러지는 수처 리장으로 들어오는 유입수의 발생원 및 유입량, 수처 리 공정의 종류 등 다양한 조건에 의해 영향을 받을 수 있기 때문에 각 공정마다 이성체별 종류 및 패턴 이 다르게 나타나는 것으로 판단된다 ${ }^{5}$.

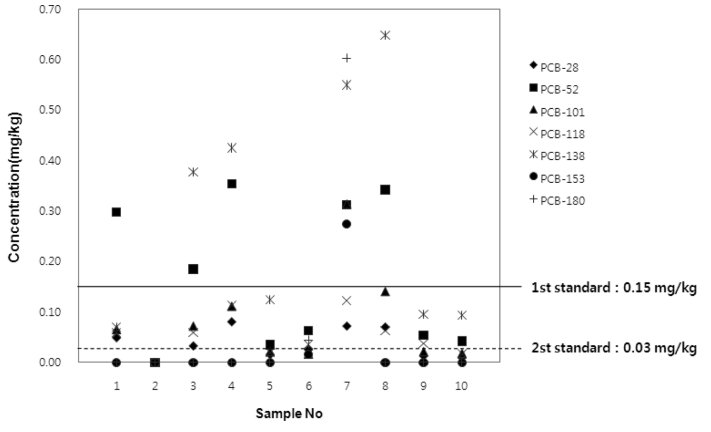

Fig. 4. PCBs concentration distribution.

\section{3. $\mathrm{PCBs}$ 함량특성}

현재 PCBs는 해양투기 폐기물 미규제 항목으로 선 정된 7 종의 개별이성체(IUPAC No. $28,52,101,108$, $138,153,180)$ 에 대해 국내 해양환경관리법 시행규칙 별표 8 해양배출처리기준 제 12 조 제 2항에도 제 1 기 준과 제 2 기준으로 제시되어 있다. 각각의 함량이 건 조 중량 기준 $0.15 \mathrm{mg} / \mathrm{kg}$ (제 1기준) 및 $0.03 \mathrm{mg} / \mathrm{kg}$ (제 2기준) 이내이어야 한다.

Fig. 4는 EWC 12공정 중금속과 플라스틱의 형태 물리 - 기계적 표면처리 시 발생하는 기계유와 에멀전, 그리스제거 처리 시 발생하는 수용성 세척액과 $\mathrm{EWC}$ 19 공정 중 폐기물의 물리화학적 처리 시 발생하는 폐유와 농축액, 폐수처리시설 중 오일과 물의 분리과 정에서 발생하는 그리스에서 발생하는 폐기물인 폐유 (4건), 기계유- 작동유(6 건) 등 총 10 건을 분석대상으 로 하여 PCBs의 배출특성을 파악하였다.

현재 해양환경관리법에서 관리되고 있는 PCBs 7 종(IUPAC No. $28,52,101,108,138,153,180)$ 의 개 별이성체를 분석한 결과, Fig. 4를 살펴보면, 제 1기준 $0.15 \mathrm{mg} / \mathrm{kg}$ 과 비교했을 때, 5 건의 시료에서 초과한 개 별이성체가 총 12 개로 나타났으며, 이들 시료는 PCB52(5 건), $\mathrm{PCB}-101$ (1 건), $\mathrm{PCB}-138$ (4 건), PCB-153(1 건) 및 $\mathrm{PCB}-180$ (1 건)으로 조사되었다. 이 시료들 중 기계유- 작동유 시료 3 개, 폐유 시료 2 개였다. PCB-138 개별이성체에서 가장 높은 $0.65 \mathrm{mg} / \mathrm{kg}$ 으로 조사되었고, 7 종의 개별이성체를 합한 값으로는 제철 제조업의 기계유 - 작동유에서 $2.247 \mathrm{mg} / \mathrm{kg}$ 으로 가장 높게 검출되었다. 또한 분석결과 T-PCBs가 제안기준 인 $1 \mathrm{mg} / \mathrm{kg}$ 을 초과하는 시료는 총 3 개 시료로, 폐유 1 개, 기계유 - 작동유 시료 2 개였다.

\section{4. 폐기물 중 유기오염물질 관리 방향}

최근 잔류성유기오염물질에 대한 규제 기준을 설정 
하여 관리하는 POPs 기술지침서가 국제협약에서 마 련되었으며, 국내에서는 잔류성유기오염물질 관리법 시행규칙에 다이옥신 및 퓨란의 함유량 기준이 제시 되어 있어 다이옥신 배출원 및 환경영향에 대한 모니 터링을 통해 관리되고 있다. 또한 $\mathrm{PCBs}$ 는 폐기물공정 시험방법에서 $\mathrm{PCBs}$ 전이성체를 관리하고 있으며, 함 량으로 해양환경관리법에서는 $\mathrm{PCBs}$ 개별이성체 7 종 에 대해 제 $1 /$ 제 2 기준을 설정하여 관리하고 있어 향 후 국가차원에서 관리효율화가 필요한 것으로 생각된 다. PAHs의 경우에는 현재 대기오염물질로 관리되고 있고, 스톡홀름협약에서 일부 검토되고 있어 $\mathrm{PAHs}$ 의 효율적인 환경관리를 위해 국제적인 관리 차원에서 검토 될 필요성이 있는 것으로 판단되었다.

\section{4. 결 론}

금속과 플라스틱 제조공정과 폐기물처리시설 · 공공 폐수처리시설 - 공공급수시설에서 발생되는 폐기물을 배출하는 국내 22 개 업체를 선정하여 현지조사하고, 오니류, 소각재, 폐유 등 폐기물 시료의 채취 및 $\mathrm{PCDD} / \mathrm{PCDFs}(17), \operatorname{PAHs}(7)$ 및 $\mathrm{PCBs}(7)$ 항목의 분석 을 통해 배출 특성을 파악하였다.

1. 비산재의 다이옥신 농도는 7.37 432.20 ng-TEQ $/ \mathrm{kg}$, 소각재는 $0.51 \sim 855.01 \mathrm{ng}-\mathrm{TEQ} / \mathrm{kg}$, 분진은 $0.37 \sim 385.81$ $\mathrm{ng}-\mathrm{TEQ} / \mathrm{kg}$ 범위로 나타났다. POPs에 제시된 규제기 준 $15,000 \mathrm{ng}-\mathrm{TEQ} / \mathrm{kg}$ 를 초과하지 않았다. 특히, 폐분 쇄틀 및 분쇄물에서 발생하는 폐기물 중 분진이 385.81 $\mathrm{ng}-\mathrm{TEQ} / \mathrm{kg}$ 로 가장 높게 검출되었으며, $2,3,4,7,8-\mathrm{PeCDF}$ 가 각 시료의 전체 $\mathrm{TEQ}$ 값의 28 34\%로 차지하는 비 율이 제일 높은 것으로 나타났다. 또한 외국자료와 비 교 검토 시 다이옥신의 함량농도가 낮은 것으로 조사 되었다. 국내에서는 잔류성유기오염물질 관리법 시행 규칙에 다이옥신 및 퓨란의 함유량 기준이 제시되어 있어 다이옥신 배출원 및 환경영향에 대한 모니터링 을 통해 관리되고 있다.

2. 공정오니의 PAHs 평균 함량농도는 0.0075 2.9225 $\mathrm{mg} / \mathrm{kg}$, 폐수처리오니는 $0.0035 \sim 1.6716 \mathrm{mg} / \mathrm{kg}$ 범위로 나타나 국내 해양환경관리법의 규제기준을 모두 만족 하는 것으로 나타났다. 벤젠고리가 적은 3 개의 $\mathrm{PAH}$ 는 acenaphthene $>$ naphthalene $>$ fluorene $>$ phenanthrene $>$ acenaphtylene $>$ anthracene 순으로 나타났다. 또한 전 체적으로 공정오니 및 폐수슬러지의 PAHs 농도는 외 국의 경우와 비교하여 다소 낮은 것으로 판단되며, 현 재 PAHs는 대기오염물질로 관리되고 있고, 스톡홀름
협약에서 일부 검토되고 있어 $\mathrm{PAHs}$ 의 효율적인 환경 관리를 위해 국제적인 관리 차원에서 검토 될 필요성 이 있는 것으로 판단되었다.

3. 현 해양환경관리법에 규제기준이 적용되는 $\mathrm{PCBs}$ 7 종을 분석한 결과(제 1 기준 $0.15 \mathrm{mg} / \mathrm{kg}$ 비교) 검출 농도는 $0.0 \sim 0.65 \mathrm{mg} / \mathrm{kg}$ 으로 나타났으며, 일부 기계유 및 작동유에서 PCB-52, PCB-101, PCB-138, PCB-153 및 $\mathrm{PCB}-180$ 개별이성체가 초과되었다. $\mathrm{PCB}-138$ 개별 이성체에서 가장 높은 $0.65 \mathrm{mg} / \mathrm{kg}$ 으로 조사되었고, 7 종의 개별이성체를 합한 값으로는 제철 제조업의 기 계유 - 작동유에서 가장 높게 검출되었다. 현재 해양환 경관리법에서는 $\mathrm{PCBs}$ 개별이성체 7 종에 대해 제 $1 /$ 제 2 기준을 설정하여 관리하고 있어 향후 국가차원 에서 관리효율화가 필요한 것으로 판단된다.

\section{참고문헌}

1. EU, 'Interpretation of the definition and classification of hazardous wastes (second edition version 2.1)', Environment Agency, 2005.

2. US EPA, 'RCRA Orientation Manual', 2006.

3. W. Wayne Brubaker and Ronald A, Hites, Environ, Sci. Technol., 31, 1805-1810 (1997).

4. J. L. Stevens, G. L. Northcott, G. A. Stern, G. T. Tomy and K. C. Jones, Environ, Sci. Technol., 37, 462-467 (2003).

5. P. Oleszczuk, Chemosphere, 65, 1616-1626 (2006).

6. J.-H. Kim, J. Environ. Sci., 13, 357-367 (2000).

7. J.-J. Nam, K.-H. So, W.-K. Park, N.-J. Cho and S.-H. Lee, J. Environ. Sci., 11, 367-373 (2002).

8. K.-Y. Lee, C.-S. Chung, Y.-I. Kim, H.-K. Lee and G.H. Hong, J. Environ. Sci., 14, 413-425 (2005).

9. National Institute of Environmental Research, 'A study on design of the marine pollution monitoring systemand trend of coastal pollution', 1996.

10. National Institute of Environmental Research, 'A study on the development of monitoring technique for trace organic pollutant discharging unit', 1996.

11. National Institute of Environmental Research, 'Establishment of new hazardous substances and development of analytical method in specified wastes(I)', 2004.

12. National Institute of Environmental Research, 'Establishment of new hazardous substances and development of analytical method in specified wastes(II)', 
2005.

13. National Institute of Environmental Research, 'Extension on Regulation Items of Unregulated Hazardous Substances in Specified Wastes(I)', 2006.

14. National Institute of Environmental Research, 'Extension on Regulation Items of Unregulated Hazardous Substances in Specified Wastes(II)', 2007.

15. Yu-Min, C., Wen-Pin, F., Wen-Chien, D., Hsing-Cheng, H., Chao-Hsiung, W. and Ching-Ho, Cl., J. Hazardous Mater., 192, $521-529$ (2011).

16. H. Wichmann, M. Kolb, C. Jopke, M. Alawi and M. Bahadir, Chemosphere, 65, 1778-1783 (2006).

17. H. Hagenmaier, J. She and C. Lindig, Chemosphere, 25, 1449-1456 (1992).

18. S. Hermes, E. Marc, L. Matine, Gao, Yue, C. Adeline, B. Gabriel, G. Severine, E. Ward and B. Willy, Chemosphere, 85, 203-209 (2011).

19. 野馬辛生, 松藤康司, 高田光康, 友田啓二郎, “一般廢 棄物最綜處分場におけるダイオキシン類の收支’, 日 本廢暂物學會論文誌, 11, 297-306 (2000).
20. J.-Y. Kim, 'A study of pre-treatment method for analysis of dioxins in liquid and solid wastes', The University of Seoul, 2008.

21. S. Sakai, S. Urano and H. Takatsuki, Waste Management, 20, 241-247 (2000).

22. M. Osako, Y.-J. Kim and D.-H. Lee, Chemosphere, 48, 849-856 (2002)

23. WHO, 'Non-heterocyclic polyclclic aromatci hydrocarbons, Geneva', International program on chemical safety, 1997.

24. M. D. Webber, H. R. Rogers, C. D. Watts, A. B. A. Boxall, R. D. Davis and R. Scoffin, Sci. Tot. Environ., 185, 27-44 (1996).

25. S. Perez, Guillamon, M. and Barcelo, D., J. Chromatogr., 938, 57-65 (2001).

26. Jiayin, Dai, Muqi, xu, Jiping, Chen, Xiangping, Yang, Zhenshan, Ke, Chemosphere, 66, 353-361 (2007).

27. R. Y. Shen, Y. M. Luo, G. Y. Zhang, Y. Teng, Z. G. Li, L. H. Wu, Pedosphere, 17, 373-382 (2007). 